\title{
Family Therapy
}

National Cancer Institute

\section{Source}

National Cancer Institute. Family Therapy. NCI Thesaurus. Code C93347.

A form of psychological counseling for the purpose of assisting family members to improve communication and resolve conflicts. 